\title{
Advanced breast cancer in a case of Down syndrome: Presenting a rare occurrence from Mankweng Hospital breast oncology clinic, Limpopo Province, South Africa
}

\author{
J G Mthembu, MB ChB; M M Z U Bhuiyan, MB BS, DTH, FRCS (Glasgow), MMed (Surg) \\ Department of General Surgery, Mankweng Hospital, University of Limpopo, Polokwane, South Africa
}

Corresponding author: M M U Bhuiyan (bhuiyanmirza@gmail.com)

Down syndrome is a genetic condition characterised by the presence of all or part of an extra chromosome 21 and is linked to a spectrum of medical and phenotypic features. Chromosome 21 is associated with tumour suppressor gene expression. Individuals with trisomy 21 have tend to have societal and hormonal risk factors for breast cancer. Here, we present a case of a 26 -year-old female patient who presented at Mankweng Hospital breast oncology clinic with a left breast lump. She was born with downs syndrome and early on from birth was noted to have hypothyroidism and no other associated congenital defects. This young lady and her mother started noticing a lump in her left breast, which had been progressively growing over the past 2 years. It was not painful, was no associated with skin changes or nipple discharge and no axillary masses were noted.

S Afr Med J 2021;111(11b):1155-1156. https://doi.org/10.7196/SAMJ.2021.v111i11b.16103

Down syndrome is a genetic condition characterised by the presence of all or part of an extra chromosome 21 and is linked to a spectrum of medical and phenotypic features. ${ }^{[1-3]}$ Chromosome 21 is associated with tumour suppressor gene expression, and the presence of the extra chromosome allows for some favourable effects, making it one of the most powerful natural protection agents against many solid tumours such as breast cancer in women. ${ }^{[3]}$ On the other hand, individuals with trisomy 21 tend to have societal and hormonal risk factors for breast cancer, including frequent nulliparity, lack of breastfeeding, physical inactivity and high body mass index, ${ }^{[4]}$ and unfortunately they are also prone to blood cancers such as leukaemia. ${ }^{[5]}$

The life expectancy of individuals living with Down syndrome has increased markedly from 25 to 60 years in the past 30 years. ${ }^{[6]}$ With that came questions as to whether screening policies for breast cancer should also apply to people with Down syndrome as compared with the general population. In particular screening policies such as mammography have been looked at. It was found that it did not serve much of a clinical benefit and to be financially costly. The cost per finding was high, hence the benefit of mammograms is questionable, and the potential for harm appears to be greater as studies have demonstrated that $<1 \%$ of the women with Down syndrome develop breast cancer. ${ }^{[6-9]}$

Dey et al. ${ }^{[2]}$ reported the first case of triple negative breast cancer, and we report a similar case in a 26-year old woman with breast cancer in Down syndrome subtype luminal A. We are hoping to bring further insights into this rare condition and spark research that will assist in gaining more insights into this condition. Ethical approval was obtained from Pietersburg/Mankweng Hospital Research Ethics Committee (ref. no. PMREC 26 MAY UL 2021/B).

\section{Case}

A 26-year-old female patient presented at Mankweng Hospital breast oncology clinic as a referral from a peripheral hospital. She was born in a rural township as one of six siblings. At a young age, her mother noticed that her development was grossly delayed compared with the other children. She was born with Down syndrome and was noted to have hypothyroidism. No other associated congenital defects were detected at birth. She was solely cared for by her family and was never able to go to school due to need for special schooling and the family's financial constraints.

This young lady and her mom started noticing a lump in her left breast, which had been progressively growing over the past 2 years. It was not painful, had no associated skin changes or nipple discharge, and no axillary masses were noted. Menarche was reported to have been at 15 years of age, she experienced regular menstrual periods, was not on contraception and has never been pregnant.

Although she was noted to have low thyroid levels at birth, she was not on treatment and was clinically euthyroid. She had no previous operations and no comorbid conditions of note. The patient had completed neo-adjuvant therapy within a week of presenting to the clinic. Prior to chemotherapy, she was assessed as stage 4 breast cancer, with a tumour size of $7 \mathrm{~cm}$ in its greatest diameter in the left upper outer breast quadrant. There was no skin or chest involvement, but there was ipsilateral axillary lymph node involvement and metastasis to the thoraco-lumbar spine detected on bone scan. Family history as well as social history was non-contributory. Upon examination, she was found to be of short stature and had physical features in keeping with Down syndrome. Vitals were stable, with blood pressure at 100/67 $\mathrm{mmHg}$ and pulse at 75 beats per minute. She was apyrexial and weighed $65.5 \mathrm{~kg}$. Breast examination showed asymmetrical breasts with left breast showing a bulge over the upper outer quadrant. No skin changes, and no palpable axillary lymph nodes. There was a palpable mass on the outer upper quadrant that was $5 \mathrm{~cm}$ in its widest diameter. It was not attached to the skin of the chest wall. The cancer was clinically stage 4 , with bone metastasis to the 9th and 5th lumbar vertebrae. The rest of the. The rest of the systematic examination was unremarkable. Histology results from a core biopsy confirmed an infiltrating ductal subtype/carcinoma of no special type. Modified Nottingham-Bloom-Richardson grading score was a total score of 7 (tubules $=3$, pleomorphism $=3$, mitoses $=1$ ), making it a grade 2 or moderately differentiated adenocarcinoma. Immunohistochemistry revealed that the cells were oestrogen 
receptor positive, progesterone receptor positive, c-erbB positive and $8 \%$ of the cells were Ki-67 positive, making it a luminal B (HER2positive) molecular subtype. Mammogram findings were breast imaging - reporting and data system (BI-RADS) 5, which was highly suggestive of malignancy on the left breast. Bone scan revealed bone metastasis localised to the 9th thoracic and 5th lumbar vertebrae. Tumour marker (CA 15-3) was 7. The patient had a good clinical response to chemotherapy and a simple mastectomy was done.

\section{Discussion}

This case is similar to the previously described case of triple negative breast cancer in Down syndrome. ${ }^{[2]}$ However, to the best of our knowledge, it is a first of its kind to be described as an advanced stage 4 luminal B (HER2+) breast cancer in an African female. Among the many genes expressed in chromosome 21 , of particular importance is runx1. Runt-related transcription factor 1 (RUNX1), also known as acute myeloid leukaemia 1 (AML1) protein or core-binding factor subunit alpha-2 (CBFA2), is a protein that is encoded by the runx1 gene in humans. ${ }^{[10]}$ RUNX1 plays a critical role in the early stages of haematopoiesis, is often expressed in breast epithelium, and is deregulated during tumorigenesis. It has been noted that runxl functions as both an oncogene and tumour suppressor gene in breast cancer, acting as a tumour suppressor in oestrogen receptorpositive tumours and an oncogene in oestrogen receptor-negative tumours. ${ }^{[10]}$ Understanding the role of RUNX1 does provide some insight into why individuals with Down syndrome have a higher risk of leukaemia and a reduced case frequency of breast cancer. More studies are needed to further clarify this, and hopefully in future we will be able to propose screening techniques for individuals living with Down syndrome who may have an increased risk of also developing breast cancer rather than using the same screening techniques used for screening non-Down syndrome patients, which has been shown to be of no clinical benefit and is costly. ${ }^{[8]}$

The patient in the case study had breast cancer, which was classified with the use of immunohistochemistry as luminal B (oestrogen receptor-positive, progesterone receptor-positive, HER2+ and Ki 67 of 8\%) molecular subtype. Based on a study conducted at Third Hospital of Nanchang City ${ }^{[1]}$ over the period 2005 - 2015, luminal B was found to the commonest subtype, and the majority of the affected individuals were below the age of 50 years $(p=0.018)$. Furthermore, luminal B has been associated with unfavourable clinical outcomes such as poorer disease-free survival, increased risk of early relapse, appears to be limited to the early period after surgery and within the first 5 years after diagnosis, predisposition to relapse in bone and pleura similar to luminal $\mathrm{A}$, with bone metastasis more common than lung, relative insensitivity to endocrine therapy compared with luminal A subtype and relative insensitivity to chemotherapy compared with basal-like and HER2positive subtypes. ${ }^{[12-14]}$ With such poor clinical outcomes, the need for early detection, diagnosis and individualised treatment strategies remains of crucial importance, more so for individuals living with Down syndrome, as other than having intellectual disability, social and financial constraints, they suffer from other medical conditions that can alter adherence to treatment and follow-up as luminal-B breast cancer has been shown to have poor response to hormonal and chemotherapy. ${ }^{[13]}$ Management stills remains a challenge for individuals with luminal-B breast cancer.

\section{Conclusion}

Luminal-B subtype remains a clinically important classification of breast cancer with prognostic and potential predictive implications. Due to the nature of the impairments in individuals with Down syndrome, such as intellectual disability, it may be difficult for early recognition of many conditions, breast cancer included, and hence poses an early detection and diagnostic challenge. For these reasons, an understanding of the relationship between breast cancer, molecular subtypes and Down syndrome is vital for researchers and clinicians, and for the education of individuals living with Down syndrome and their families, more so for the formulation of individualised treatment strategies. More research is encouraged to further guide our understanding and aid in the formulation of management protocols relevant to this population.

Declaration. None.

Acknowledgements. None.

Author contributions. Equal contributions.

Funding. None.

Conflicts of interest. None.

1. Saraydemir \$, Taşpınar N, Eroğul O, Kayserili H, Dinçkan N. Down syndrome diagnosis based on gabor wavelet transform. J Med Syst 2012;36(5):3205-3213. https://doi.org/10.1007/s10916-011-9811-1

2. Dey N, Krie A, Klein J, et al. Down syndrome and triple negative breast cancer: A rare occurrence of distinctive clinical relationship. Int J Mol Sci2017;18(6):1218. https://doi.org/10.3390\%2Fijms18061218

3. Asim A, Kumar A, Muthuswamy S, Jain S, Agarwal S. Down syndrome: An insight of the disease. Biomed Sci 2015;22(1):41. https://doi.org/10.1186\%2Fs12929-015-0138-y

4. Martel-Billard C, Cordier C, Tomasetto C, Jégu J, Mathelin C. Trisomy 21 and breast cancer: A genetic abnormality which protects against breast cancer?. Gynaecol Obstet Fertil 2016;44(4):211-217. https:// doi.org/10.1016/j.gyobfe.2016.02.016

5. Ehara H, Ohno K, Ito H. Benign and malignant tumors in Down syndrome: Analysis of the 1514 autopsied cases in Japan. Pediatr Int 2011;53(1):72-77. https://doi.org/10.1111/j.1442-200x.2010.03189.x 6. Chicoine B, Roth M, Chicoine L, Sulo S. Breast cancer screening for women with Down syndrome: Lessons learned. Intellect Dev Disabil 2015;53(2):91-99. https://doi.org/10.1352/1934-9556-53.2.91

7. Hasle H, Friedman JM, Olsen JH, Rasmussen SA. Low risk of solid tumors in persons with Down syndrome. Genet Med 2016;18(11):1151-1157. https://doi.org/10.1038/gim.2016.23

8. Rethoré MO, Rouëssé J, Satgé D. Cancer screening in adults with Down syndrome, a proposal. Eur J Med Genet 2020;63(4):103783. https://doi.org/10.1016/j.ejmg.2019.103783

9. Alagoz O, Hajjar A, Chootipongchaivat S, et al. Benefits and harms of mammography screening for women with Down syndrome: a collaborative modeling study. J Gen Intern Med 2019;34(11):23742381. https://doi.org/10.1007/s11606-019-05182-5

10. Sood R, Kamikubo Y, Liu P. Role of RUNX1 in haematological malignancies. Blood 2017;129(15):20702082. https://doi.org/10.1182/blood-2016-10-687830

11. Li Z-H, Hu P-H, Tu J-H, Yu N-S. Luminal B breast cancer: Patterns of recurrence and clinical outcome. 1. Li Z-H, Hu P-H, Tu J-H, Yu N-S. Luminal B breast cancer: Patterns of recurrence
Oncotarget 2016;7(40):65024-65033. https://doi.org/10.18632/oncotarget.11344

12. Tran B, Bedard PL. Luminal-B breast cancer and novel therapeutic targets. Breast Cancer Res 2011;13(6):221. https://doi.org/10.1186/bcr2904

13. Ades F, Zardavas D, Bozovic-Spasojevic I, et al. Luminal B breast cancer: Molecular characterisation, clinical management, and future perspectives. J Clin Oncol 2014;32(25):2794-2803. https://doi. org/10.1200/jco.2013.54.1870

14. Kudela E, Samec M, Koklesova L, et al. miRNA expression profiles in luminal A breast cancer implications in biology, prognosis, and prediction of response to hormonal treatment. Int J Mol Sci 2020;21(20):7691._https://doi.org/10.3390\%2Fijms21207691

Accepted 5 September 2021. 